\title{
TRABALHADORES DO BRASIL, MIS QUERIDOS DESCAMISADOS: UMA (RE)INVENÇÃO SOBRE OS TRABALHADORES NO VARGUISMO E NO PERONISMO ${ }^{* *}$
}

\author{
TRABALHADORES DO BRASIL, MIS QUERIDOS DESCAMISADOS: \\ A (RE)INVENTION ABOUT THE WORKERS IN VARGUISM AND PERONISM
}

\author{
Mayra Coan Lago ${ }^{(* *)}$ \\ Universidade de São Paulo, São Paulo (Sp), Brasil
}

Resumo: Pretendemos estudar os imaginários sociais sobre os trabalhadores, produzidos pelo discurso oficial, no varguismo e no peronismo. Posteriormente, pretendemos comparar os imaginários sociais sobre os trabalhadores no Estado Novo, com os do Primeiro Peronismo, visando compará-los. Para tal, analisaremos a dimensão simbólica, a partir do estudo dos discursos políticos das festas cívicas dos Primeiros de Maio e a dimensão "material", a partir do estudo da legislação trabalhista e das políticas sociais promulgadas nestes momentos. A partir da análise da dupla dimensão, propomos a ideia de uma (re)invenção sobre os trabalhadores.

Palavras-chave: Trabalhadores; Varguismo; Peronismo.

Abstract: First, at all, this paper aims to study the social imaginary about workers produced by the official speech in varguism and peronism. Later, we compare the social imaginary about the workers in the Estado Novo with the First Peronism trough the symbolic dimension. The documents analyzed derived from the First of May civic festivals, labor law and social policies promulgated in these moments. Our analysis propose the idea of a (re) invention about workers.

Key-words: Workers; Varguism; Peronism, Workers in Latin America.

(*) O trabalho apresenta os principais resultados da dissertação de mestrado intitulada "Trabalhadores do Brasil, Mis Queridos Descamisados: uma (re)invenção do trabalhador no varguismo e no peronismo" defendida no Programa de Pós-graduação Interunidades em Integração da América Latina da Universidade de São Paulo em abril de 2015, sob a orientação do Professor Doutor Julio Manuel Pires.

(**) Mestre pelo Programa de Pós-graduação em Integração da América Latina da Universidade de São Paulo (PROLAM/ USP). E-mail: <mcoann@hotmail.com>. Recebido em:13.03.2015; aceito em: 24.06.2015. 


\section{INTRODUÇÃO}

A entrada na cena política nacional de Getúlio Vargas no Brasil, na década de 1930, e a de Juan Domingo Perón na Argentina, na década de 1940, demarcam em cada um dos países o início de uma série de transformações nos âmbitos político, econômico, social e cultural. Os governantes, embora estivessem inseridos em contextos distintos, consideravam que a mudança era imprescindível para a "continuidade" de seus países e, assim, eles deveriam ser os "verdadeiros" representantes destas mudanças e dos "novos" países.

No Estado Novo (1937-1945) de Vargas e no Primeiro Peronismo (1946-1955) de Perón, o papel do Estado ${ }^{(1)}$, do governante e da sociedade seriam repensados. Ademais, para os governantes, a entrada em cena política de uma parte da sociedade esquecida até então era fundamental: os setores populares. Dentre a gama dos atores políticos que compunham os "setores populares", identificamos os trabalhadores como aqueles que receberam especial atenção dos governantes, sendo sua força política e apoio fundamentais para a realização dos projetos políticos propostos.

Para Maria Helena Capelato (2009), com o advento do Estado Novo ocorreu a consolidação da política de massas no Brasil que, na década seguinte, foi introduzida na Argentina. De acordo com José Luis Beired (1999), a "política de massas" pode ser caracterizada pela "quebra" da antiga ordem e a construção de novos sistemas de poder, baseados no reconhecimento das maiorias sociais. Ainda, de acordo com o historiador, dois vetores fundamentais balizaram esta "quebra" na América Latina: os Governos que desenvolveram instrumentos de integração e mobilização dos setores sociais; e os movimentos políticos, de extração popular, que buscaram alcançar o poder, seja por meio de eleições ou pelo uso da força. O terceiro vetor "adicional" seria as transformações das estruturas sociais que acompanharam a industrialização.

Os regimes nacional-populares desenvolveram uma política de massas por meio de um eficiente sistema de comunicação, composto pelo rádio, pelo cinema e a pela imprensa, e por espetáculos de poder, isto é, as festas cívicas e as manifestações de massa em espaços abertos com a presença do líder, inspiradas nos regimes nazifascistas da Europa. Para complementar estes dispositivos, havia a censura e a repressão aos opositores (CAPELATO, 2009).

No tocante aos trabalhadores, os governantes propunham a reformulação do trato da "questão social". Como Angela de Castro Gomes (2002) demonstrou, no caso brasileiro, e nós consideramos também para o caso argentino, tal reformulação seria composta pela combinação de aspectos materiais, como as políticas sociais e a legislação trabalhista, e de aspectos "imateriais" ou simbólicos, referentes aos imaginários sociais dos trabalhadores, tocando em temas delicados como a cidadania, a "consciência política", a identidade coletiva e a participação política.

Para tratarmos do que compreendemos por imaginários sociais, utilizaremos as contribuições de Bronislaw Bazcko (1985) e de Patrick Charaudeau (2013). Vale dizer

(1) Neste trabalho, entendemos e utilizaremos a noção de Estado, sob um sentido mais amplo e geral, proposto por Max Weber (2004), isto é, o Estado como uma comunidade humana, constituído por uma autoridade (ou um governo) e um território. 
que não pretendemos recuperar o histórico do termo ou do conceito, senão apresentar alguns aspectos do que entendemos por imaginários sociais, de seu papel nas sociedades e a sua relação com a dimensão política.

O primeiro dos aspectos a ser mencionado é que os imaginários sociais não são, como dão a entender seu emprego corrente, aquilo que se opõe à realidade. Como constatou Bazcko (1985), os sistemas de representação produzidos em diferentes épocas não desassociou o "verdadeiro" e o "ilusório", pelo contrário, associou-se por meio de um jogo complexo e dialético. A partir das ilusões que uma época cria de si própria, ela manifesta e esconde, ao mesmo tempo, a sua "verdade", tal como o lugar que lhe cabe na história.

O segundo aspecto a ser sublinhado é que os imaginários sociais são inventados, construídos, e não dados. Dizer que são construídos não significa afirmar que sejam construções sólidas, rígidas, senão que seus elementos são selecionados, relacionando significantes (imagens, palavras) e significados (representações) que fazem sentido para determinada sociedade, época, contexto e grupo.

Todas as épocas tiveram as suas modalidades específicas de imaginar, reproduzir e renovar os imaginários sociais, tal como as modalidades específicas de acreditar, de sentir e de pensar. Neste sentido, as produções imaginárias não são isomorfas, senão polissêmicas e ambivalentes. O terceiro aspecto é justamente a multiplicidade e a heterogeneidade destes imaginários sociais, que vão ter as particularidades e especificidades de acordo com as classes, sociedades, países e do contexto sócio-histórico em que forem produzidos e (re)produzidos.

Baczko (1985) constatou que no centro do imaginário social se encontra o problema do poder legítimo ou o problema da legitimação do poder. Assim, o quarto aspecto a ser sublinhado é a relação dos imaginários sociais com o poder. A elaboração de imaginários sociais é parte integrante de qualquer regime político e é por meio dos imaginários sociais que se pode atingir não apenas a cabeça, mas também o coração.

Para desempenhar seu papel de "espelho identitário", os imaginários fragmentados, instáveis e essencializados têm necessidade de ser materializados. Se, por um lado, precisam ser materializados, por outro, precisam ser sustentados por uma racionalização discursiva, o que Charaudeau (2013) denominaria como imaginários sociodiscursivos, isto é, os imaginários sociais que existem e são reproduzidos nos discursos, sobretudo nos discursos políticos.

A partir das considerações apresentadas, este trabalho está inserido e tem como objetivo principal estudar os imaginários sociais sobre os trabalhadores, produzidos pelo discurso oficial, no varguismo e no peronismo e, posteriormente, compará-los. Para lograr o objetivo, selecionamos os discursos políticos das festas cívicas dos Primeiros de Maio, ocorridas no varguismo e no peronismo.

Com relação aos espetáculos de poder, vale dizer que os mesmos compunham o calendário festivo do Estado Novo e do Primeiro Peronismo a fim de produzirem e reproduzirem imagens de legitimidade, coesão e apoio dos brasileiros e argentinos, sobretudo dos trabalhadores, aos "grandes líderes" da nação e a obra de "reconstrução" que estava sendo realizada, em que se reafirmava a distinção entre o "velho" e o "novo" Brasil e a Argentina. 
Entre os discursos políticos de Vargas e Perón e os espetáculos de poder, do varguismo e do peronismo, selecionamos os Primeiros de Maio por dois motivos principais: o primeiro por considerarmos que os discursos políticos, inseridos no gênero textual, são textos que são escritos para serem lidos, isto é, têm um caráter mais planejado. O segundo é pelo fato do Primeiro de Maio ser, historicamente, uma data expressiva para os trabalhadores, que foi apropriada e ressignificada por Vargas e Perón a fim de reforçar a identificação e os "elos" entre eles e os trabalhadores, informar e ressaltar o papel e os imaginários sociais sobre os trabalhadores em seus governos, além de divulgar as próximas políticas relacionadas ao mundo do trabalho, isto é, a legislação trabalhista e a política social.

Selecionamos o método comparativo pois concordamos com Maria Ligia Prado (2005), ao afirmar que a comparação, sobretudo do Brasil com os demais países da América Latina, é rica em potencialidades e contribui para a reflexão sobre novos problemas e questões.

A partir do estudo destes discursos políticos propomos, a ideia de uma (re)invenção sobre os trabalhadores no varguismo e no peronismo. (Re)invenção porque consideramos que, nos momentos anteriores ao varguismo e ao peronismo, isto é, antes das décadas de 1930 e 1940, sobretudo no tocante aos trabalhadores, houve "invenções" seja por parte deles ou por parte do Estado, sobretudo dos governantes. Assim, tais invenções e representações, seja pelos próprios trabalhadores ou sobre eles, ocorreram das mais variadas e complexas formas.

Não obstante, é em 1937, no caso de Vargas e, em 1946, no caso de Perón, que tal reinvenção seria consagrada pelo discurso oficial. A (re)invenção seria composta pela dupla dimensão, a simbólica, especialmente relacionada aos imaginários sociais sobre os trabalhadores, e a "material", composta pela legislação trabalhista e a política social promulgadas no período.

Quem eram estes trabalhadores? Como foram "imaginados" e representados por Vargas e Perón? Como os governantes construíram e reproduziram as imagens dos "elos" com os trabalhadores? Eis algumas das perguntas que nortearão nossa reflexão.

Para lograr o objetivo, este trabalho tem duas partes, além desta introdução e das considerações finais, em que procuramos apresentar os discursos oficiais, a partir dos discursos políticos de Vargas e de Perón, sobre o trabalhador e demonstrar como ocorreram as reinvenções, tal como as particularidades das mesmas no Brasil e na Argentina.

Cabe dizer que, embora tratemos do discurso oficial produzido sobre os trabalhadores, não consideramos as teorias sobre o populismo, propostas inicialmente por Francisco Weffort (2003), Gino Germani (1962), entre outros, como forma de estudo deste tema, principalmente pelas características gerais das teorias que consideram o trabalhador como massa amorfa, facilmente manipulável e inconsciente politicamente. Deste modo, este trabalho se inspira em autores e trabalhos relativamente recentes como os de Miguel Murmis e Portantiero (2012), Jorge Ferreira (2001), Juan Carlos Torre (2012), Capelato (2009), entre outros, que procuram mostrar as especificidades e particularidades deste período complexo da história política brasileira e argentina, dos trabalhadores 
e do esforço e das estratégias utilizadas pelo Estado Novo e pelo Primeiro Peronismo para a produção e reprodução do suposto elo entre Vargas, Perón e os trabalhadores, da imagem de "pai dos pobres" e "amigo dos trabalhadores" e da "doação" da legislação trabalhista, para além de algo "natural" e facilmente construído.

\section{IMAGENS DO DISCURSO OFICIAL SOBRE O TRABALHADOR NO VARGUISMO (1937-1945)}

Em 1930, com a denominada "Revolução de 1930", o discurso oficial iniciava a reprodução de novas imagens sobre o trabalho e o trabalhador, sobre o trato da questão social e sobre a relação do Estado com os trabalhadores e do governante com os brasileiros a partir da combinação de uma dupla dimensão, composta pela dimensão simbólica, relacionada às imagens sobre o trabalho e o trabalhador, e pela "material", relacionada à legislação trabalhista. A outra face da reconfiguração do discurso oficial sobre a relação do Estado com os trabalhadores era a violência e a repressão aos movimentos dos trabalhadores e aos demais opositores do regime.

Ainda que as "novas" imagens tenham raízes no governo "provisório" é no Estado Novo que seriam consagradas. No dia 10 de novembro de 1937, Vargas reiniciava o governo que perduraria por quase uma década. Novamente, o "projeto político" de Vargas, anunciado no dia do golpe, tinha como principal objetivo a reconstrução do Brasil a começar de um "novo" tipo de governo, governante, brasileiros e trabalhadores.

O Estado Novo foi instaurado com a dissolução do Congresso e a criação da Carta Constitucional, que legalizou um aparato de medidas destinadas a estreitar o espaço das liberdades políticas, a controlar os movimentos dos trabalhadores, a disciplinar a mão de obra e a industrializar o país (CAPELATO, 2009). Nesse cenário, emergiu o Estado intervencionista que fundou sua legitimidade na defesa do desenvolvimento econômico, na integração territorial, política e social, na ampliação dos direitos sociais, buscando a construção do progresso dentro da ordem. O regime que durou quase dez anos, contou com os setores majoritários das Forças Armadas, da Igreja, de alguns setores de trabalhadores e de proprietários.

No Estado Novo, o governante intensificou o uso das imagens do "novo" tempo, tal como da mudança e das "benesses" de seu governo relacionadas, sobretudo, ao mundo do trabalho e à modernização do Brasil. Nos espetáculos de poder, o discurso oficial reproduzia imagens de apoio e de coesão ao novo momento, que eram difundidas para os "brasileiros", de modo geral, e aos trabalhadores, de modo específico.

Com relação aos espetáculos de poder selecionados, ainda que tivessem especificidades, havia algumas características em comum, como: apresentações artísticas; os discursos políticos do governante; e a exaltação ao governante, por "proporcionar" as benesses trabalhistas, a partir da presença e dos desfiles, natural ou forçado, dos trabalhadores sindicalizados com placas de apoio aos governantes (LAGO, 2015). No caso dos Primeiros de Maio, os espetáculos continham uma programação mais extensa, em que figuravam discursos políticos também dos membros do MTIC e "presentes" durante a festa, como a legislação trabalhista do período. 
De acordo com Capelato (2009), no Estado Novo, a dimensão privada e pública do homem era definida pela relação trabalhador/cidadão, isto é, membro socialmente útil do Estado $^{(2)}$. O trabalho, antes forma de escravidão, passara a ser visto como forma de emancipação da personalidade, que valorizava o homem e tornava-o digno de respeito e de proteção da sociedade.

O trabalhador deveria ser melhor remunerado para não apenas elevar seu padrão de vida como também aumentar o consumo e melhorar as condições do mercado interno. Para compor o projeto político do Estado Novo, era preciso dar continuidade às imagens reinventadas dos trabalhadores. A dicotomia "velho" trabalhador e "novo" trabalhador seria amplamente utilizada por Vargas. O marco "1930" e sua consagração em "1937" seriam utilizados como contraste aos momentos anteriores, em que os trabalhadores não eram considerados pelos governantes. Na situação anterior, Vargas reproduzia a imagem dos trabalhadores como sem direitos, sem proteção, como basicamente eleitores dos políticos corruptos, como podemos notar no discurso político do Primeiro de Maio de 1940:

Falando em momento como este, diante de uma multidão que vibra de exaltação patriótica, não posso deixar de pensar como os nossos governantes permaneceram, durante tanto tempo, indiferentes à cooperação construtiva das classes trabalhadoras. Relegados a existência vegetativa, privados de direitos e afastados dos benefícios da civilização, da cultura e do conforto, os trabalhadores brasileiros nunca obtiveram, sob os Governos eleitorais, a menor proteção, o mais elementar amparo. Para arrancar-lhes o voto, os políticos profissionais tinham de mantê-los desorganizados e sujeitos à vassalagem dos cabos eleitorais. A obra de reparação e justiça realizada pelo Estado Novo distancia-nos, imensamente, desse passado condenável, que comprometia os nossos sentimentos cristãos e se tornara obstáculo insuperável à solidariedade nacional (VARGAS, 2011, p. 292).

O "novo" trabalhador seria educado, organizado, teria direitos e uma condição melhor de vida. A menção mais geral "trabalhadores" referia-se a imagens mais específicas, isto é, aos trabalhadores urbanos e aos trabalhadores rurais. Embora ambos fizessem parte desse projeto político, cada categoria teria sua função relacionada a imagens específicas: os trabalhadores urbanos teriam suas imagens relacionadas à industrialização, à modernização, à máquina, e ao enriquecimento do Brasil; enquanto os trabalhadores rurais teriam suas imagens relacionadas à tradição, à nacionalidade e à produção para o consumo nacional e internacional. Além destas duas categorias, Vargas também reproduziria imagens do trabalhador relacionado à família e, nesse sentido, à ampliação de benefícios aos demais membros (LAGO, 2015).

No discurso oficial, a imagem de consideração dos trabalhadores era acompanhada do diferencial do governo, isto é, da conciliação e cooperação das classes, substituindo a antiga luta de classes, sendo Vargas o maior "conciliador" das classes.

(2) Vale recordar os ausentes no discurso oficial, como os desempregados, que seriam os "maus brasileiros". O número de desempregados nessa época era muito grande e, assim, a enorme massa dos pobres sem trabalho não se integrava na categoria de "bom" brasileiro ou mesmo de cidadão. Ficando à margem da relação presidente/povo trabalhador, essas pessoas não tinham identidade, não "existiam", isto é, não compunham esta sociedade, além de serem vistas como perigo e ameaça à harmonia da sociedade (CAPELATO, 2009). 
Combinada com estas imagens sobre os trabalhadores no discurso oficial estaria a da "gratidão" e do "apoio" ao governante, que lhes "educou" e tudo lhes doou. Vale observarmos que estas imagens seriam refletidas e utilizadas na apropriação da data simbólica dos trabalhadores para demarcar e reafirmar o "novo" e o "velho" tempo:

Trabalhadores: Como vedes, no regime vigente, participais diretamente das atividades organizadoras do Estado, em contraste flagrante com a situação anterior a 1930, quando os vossos interesses e reclamos não eram, sequer, ouvidos e morriam abafados nos recintos estreitos das delegacias de polícia. Hoje, tendes, no maior e mais belo edifício público do País, a vossa própria casa, e nela penetrais sem constrangimento (VARGAS, 2011, p. 89).

O discurso oficial procurava reproduzir imagens de um governo dos trabalhadores, além de reafirmar as novas imagens já mencionadas, sobre a relação entre o Estado e os trabalhadores, sobretudo tendo como eixo a reformulação da "questão social" a partir do regime varguista. Vargas se colocava como o primeiro governante que considerou as aspirações e os interesses dos trabalhadores. Do mesmo modo, no discurso oficial, a legislação trabalhista do período teria sido "doada" pelo governante, antes mesmo dos trabalhadores pedirem, o que implica na tentativa de apagamento das lutas, demandas e aspirações históricas.

Outra forma de tentar apagar a luta dos trabalhadores encontrada nos discursos políticos era a descrição dos trabalhadores como desorganizados e com ausência de cultura. Deste modo, no discurso oficial, Vargas se colocava como aquele que organizou a classe trabalhadora, que lhe deu consciência, procurando apagar, assim, toda a histórica luta por direitos dos trabalhadores no Brasil, antes do varguismo.

Além da reafirmação de um novo tempo, o discurso oficial combinaria as ideias de educar e disciplinar, presentes nos próprios Primeiros de Maio, com os aspectos "materiais", os presentes "doados" nestas festas. Com relação à ideia de educar, a "disciplinarização" do trabalho auxiliou na criação do epíteto "pai dos pobres". Para Capelato (2009), tal epíteto sustenta a ideia do "povo criança" e do "pai", que educa seus filhos e, em troca de bom comportamento, os presenteia. Em contrapartida, os filhos reconhecem no pai, além de educador, uma autoridade que deve ser respeitada, amada e reconhecida por seus atos.

Com a entrada do Brasil na Segunda Guerra Mundial, as imagens sobre o trabalho, o trabalhador e sua relação com o governante seriam reforçadas. De acordo com Capelato (2009), o momento tornou a situação econômica e política brasileira ainda mais críticas. No tocante à situação econômica, houve o aumento do custo de vida, o racionamento de produtos básicos e de gêneros de primeira necessidade ${ }^{(3)}$. Com relação aos

(3) Além desses efeitos, Lira Neto (2013) destacou o "blecaute" à noite, submetendo as casas e ruas nas principais cidades do país à escuridão, para dificultar hipotéticos bombardeios inimigos e a gasolina que se tornou escassa, sendo possibilitada apenas a veículos oficiais. Além desses efeitos, o aspecto que mais aterrorizou a população e, principalmente, as classes médias e urbanas, foi a inflação que ameaçava corroer o poder de compra da nova moeda-o cruzeiro, instituído em 1942, em substituição ao "mil-réis". 
trabalhadores, Gomes (2002) ressalta que os "tempos de guerra" seriam marcados pela suspensão da vigência de diversos direitos trabalhistas ${ }^{(4)}$.

No tocante à situação política, a contradição entre lutar a favor da liberal-democracia ao lado dos Aliados na Europa e manter um regime autoritário no país foi acentuada. Nesse contexto, Vargas intensificaria o apelo ao apoio dos "amigos", dos "filhos", tal como a convocação de todos os trabalhadores para a "batalha da produção". Tal apelo seria sustentado pela intensa reprodução das imagens mencionadas e pelos aspectos "materiais". Com relação à dimensão "material", a legislação trabalhista teria um papel fundamental para legitimar os apelos do governante, como podemos observar em 1945, quando Vargas faz uma síntese de suas realizações para os trabalhadores:

Vitoriosa a revolução de 30, uma das primeiras iniciativas do Governo foi a criação do Ministério do Trabalho. Isso por só definia os rumos políticos daquele movimento revolucionário. Daí por diante a nossa atuação desenvolveu-se sem hesitações abrangendo todos os setores da legislação social a saber nacionalização do trabalho com lei dos Dois Terços; normas gerais e especiais de tutela do trabalho; duração do trabalho no comércio, na indústria, nos serviços públicos e atividades privadas; concessão de férias; proteção ao trabalho da mulher e do menor; contrato individual e contrato coletivo de trabalho; organização sindical; fiscalização das leis trabalhistas; justiça especial do trabalho; estabilização no emprego e indenização por acidentes; higiene, alimentação e ensino do trabalhador, com a instalação de refeitórios populares, escolas de ofícios; [...] instituição do salário mínimo, suas adaptações às condições regionais; salário adicional e possibilidade de novas revisões; amparo econômico a todas as classes de trabalhadores, com a organização dos Institutos e caixas que distribuem os benefícios comuns e especiais do seguro social, mantendo além disso a assistência médica hospitalar, financiando a construção de casas operárias e ampliando direta ou indiretamente os meios de elevar o nível profissional, melhorar a saúde e prover a segurança do lar e a educação da prole do trabalhador (VARGAS, 2011, p. 470).

A partir do uso da promulgação destas leis, Vargas também sustentava o papel, a imagem e o significado da cidadania, relacionando-a exclusivamente com a posse dos direitos sociais, sobretudo dos trabalhadores, em detrimento dos direitos civis e políticos. De acordo com Gomes (2002), ser cidadão no Estado Novo era, além de integrar o mundo definido como da política, pertencer a uma totalidade: econômica, uma vez que trabalhar era produzir riquezas; jurídica, uma vez que possuía a carteira de trabalho; e moral, uma vez que o trabalho deveria ser compreendido como um dever e um direito, ou seja, cidadania era pertencimento, relacionado diretamente à identidade nacional.

No Estado Novo, o trabalhador, embora estivesse "dignificado" e fosse um elemento importante para a base do governo, era considerado como máquina de produção, para atingir o desenvolvimento e a disciplinarização da força de trabalho. Assim,

(4) Em agosto de 1942, por exemplo, o Governo decretou a restauração da jornada de dez horas de trabalho, proibindo a utilização do instrumento legal capaz de contestar tal medida, sob o argumento do "estado de guerra". Em outubro do mesmo ano, outro decreto suspendia o direito de férias em todas as indústrias consideradas essenciais à segurança nacional. Em dezembro, mais um decreto impedia a mobilidade do trabalho nas chamadas "indústrias de guerra", o que transformava literalmente seus empregados em "desertores" em casos de falta e desistência do emprego. 
a tônica do momento, o trabalho, contribuiu para a conformação da cultura política brasileira conhecida como trabalhismo.

Para Gomes (2002), o trabalhismo pode ser compreendido como um conjunto de ideias, valores, rituais e vocabulários vinculados à promessa de justiça social. Ainda não obstante de acordo com Gomes (2002), como ideologia, projeto e cultura política, o trabalhismo lança raízes na experiência do movimento operário e sindical da Primeira República que o Estado Novo procurou negar e apagar. Em outras palavras, se o trabalhismo foi inventado no período pós-1930, não foi de forma fortuita, arbitrária e a partir do nada, senão da apropriação e da ressignificação de elementos simbólicos e das demandas e aspirações dos trabalhadores no período anterior. Essas apropriações e ressignificações podem auxiliar na compreensão do poder de significação e de mobilização de parte dos trabalhadores, revelando a releitura que as elites políticas realizaram no campo de lutas dos trabalhadores.

\section{IMAGENS DO DISCURSO OFICIAL SOBRE O TRABALHADOR NO PERONISMO (1946-1955)}

Tal como no Brasil, na Argentina, o discurso oficial sobre o trabalho e o trabalhador, tal como as raízes da reinvenção sobre os trabalhadores, iniciara antes do período conhecido como "peronismo". A partir de 1943, sob o governo da "Revolução Nacional", podemos observar uma mudança no discurso oficial sobre a questão social, tal como da relação do Estado com os trabalhadores. No governo da "Revolução", Perón acumulou os cargos de vice-presidente, Ministro de Guerra e Secretário de Trabalho e Previdência.

Desde o cargo de Secretário de Trabalho e Previdência, Perón iniciaria projeções de novas imagens sobre o trabalho, o trabalhador, a justiça social e a própria relação do governo com os trabalhadores. Combinado com estas imagens, Perón iniciaria a aproximação com os trabalhadores a partir de reuniões com sindicalistas e da promulgação da legislação trabalhista, que seria amplamente utiliza em momento posterior. A outra face do discurso oficial sobre a relação amistosa era justamente a censura e a repressão aos trabalhadores e demais opositores do regime, como o caso da Central General del Trabajo (CGT) número 2, de cunho predominantemente comunista, cuja sede foi fechada no dia 21 de julho de 1943 e suas atividades foram proibidas em todo o território nacional.

Ainda que o discurso oficial sobre a reformulação do trato da questão social fosse um aspecto em comum com o Brasil, vale ressaltar duas especificidades e diferenciações do caso argentino: o uso de imagens relacionando o trabalho à justiça social e a imagem de luta de classes, em oposição à de conciliação de classes, no caso brasileiro. Com relação à justiça social, o discurso oficial sustentava que a melhora nas condições de vida e de trabalho, compondo os principais elementos da tônica, eram indispensáveis para o progresso e prosperidade das nações.

Para lograr a justiça social, a política redistributiva deveria estar baseada no entendimento das forças dos trabalhadores, empregadores e Estado. As discórdias entre as duas primeiras forças deveriam ser mediadas pela autoridade e justiça do Estado. Não obstante, a discórdia instaurada, sobretudo no discurso oficial, entre empregadores e 
Estado impossibilitou a mediação direta e amistosa e forjou a própria imagem de luta de classes ao invés de conciliação de classes.

Estes dois aspectos distintos iniciais contribuíram para os diferentes "tons" dos discursos oficiais no varguismo e no peronismo, os quais abordaremos adiante. Em 1946, por eleições diretas, Perón foi eleito como Presidente da Argentina pelo Partido Laborista, sendo reeleito sob a sigla do Partido Peronista em 1951 e derrubado por um golpe militar em 1955.

De acordo com Capelato (2009), no primeiro governo, Perón contou com o apoio dos trabalhadores, de grupos nacionalistas, de setores das Forças Armadas e da Igreja. Vale mencionarmos o contexto econômico favorável deste primeiro momento. Com o fim da Segunda Guerra, o país devedor tornou-se credor graças à colocação de seus produtos agropecuários no mercado europeu. O Governo peronista tentou reforçar o setor industrial da economia com a ajuda do setor agrícola, reduzir a influência estrangeira na economia, sobretudo as referentes ao setor público, e outorgar para o Estado o papel decisivo na regulamentação da economia com o Plano Quinquenal (1946-1951).

O número de estabelecimentos industriais e de trabalhadores duplicou entre 1935 e 1946, sendo que a indústria passou a ser o centro dinâmico de acumulação de capital na metade dos anos 1940, ainda que a agroexportação continuasse sendo a principal fonte de divisas. Tal situação contribuiu para a melhora do nível de vida dos argentinos, tal como da propagação da imagem de "mundo feliz" ${ }^{(5)}$. Contudo, no segundo mandato, o descontentamento era visível por parte dos grupos nacionalistas e da Igreja, que acabou rompendo com o governo.

Ainda que o Primeiro Peronismo seja composto por dois governos, há aspectos comuns na consagração da reinvenção sobre os trabalhadores. Nos discursos políticos de Perón, os tempos anteriores à "Revolução de 43" eram retratados como de exploração, sofrimento, dor, miséria e injustiça. A "Revolução de 43", impulsionada também pela necessidade de se implantar a justiça social, deveria marcar um tempo novo na Argentina, que foi consagrado com a chegada de Perón ao poder.

Para comemorar, no sentido de recordar, a ascensão do peronismo, tal como para reproduzir as imagens de apoio, coesão, lealdade e legitimidade do novo governo, que foi proposto um calendário festivo, composto por diversos espetáculos de poder. Tais espetáculos de poder tinham características comuns aos brasileiros, sobretudo a composição dos desfiles, os discursos políticos dos governantes, as homenagens ao governante e os presentes da festa (que, no caso do peronismo, eram premiações).

Embora o varguismo e o peronismo apresentem aspectos semelhantes, principalmente com relação à composição dos espetáculos de poder, precisamos assinalar suas especificidades e particularidades. Para nossa reflexão, teremos dois aspectos mais amplos de análise: a breve menção sobre a participação dos trabalhadores nestes espetáculos, tal

(5) Os trabalhadores opositores do regime compunham a oposição ao "mundo feliz". Entre os estudos sobre a atuação dos trabalhadores no Primeiro Peronismo, ver Gustavo Contreras (2014), no Dossiê "Los trabajadores durante los años del primer gobierno peronista. Nuevas miradas sobre sus organizaciones, sus prácticas y sus ideas (1946-1955). 
como as imagens oficiais produzidas e reproduzidas; e os discursos políticos de Perón, integrando o discurso oficial sobre o trabalhador. Ainda que apresentadas separadamente, vale dizer que ambas se combinavam e forjavam as imagens do discurso oficial sobre o trabalhador no varguismo e no peronismo.

Com relação às imagens utilizadas e propagadas pelo discurso oficial da ditadura varguista, o "novo" trabalhador aparecia, nos relatos oficiais dos espetáculos de poder, em uma posição "passiva", sem "voz"(6), isto é, não compunha os discursos políticos da comemoração e, menos ainda, cargos do governo. Estas imagens eram combinadas com a própria tentativa do discurso oficial de procurar apagar a histórica luta dos trabalhadores no Brasil. Deste modo, Vargas tomava a "voz" dos trabalhadores, procurando projetar imagens sobre si de "pai" e líder dos trabalhadores, como mencionamos no segundo tópico deste trabalho.

No caso do peronismo, o discurso oficial procuraria produzir outros tipos de imagens sobre a relação dos trabalhadores com Perón, projetando o "novo" trabalhador em uma posição "ativa", com "voz". Além disto, no governo, alguns cargos importantes foram atribuídos aos trabalhadores sindicalizados, como da Secretaria del Trabajo y Previsión, posteriormente, Ministério do Trabalho dirigido por José Maria Freire, do grêmio dos vidraceiros, do Ministério Interior, dirigido por Ángel Borlenghi, dos empregados do comércio, entre outros.

Ainda que possamos questionar os limites de atuação dos trabalhadores em tais cargos, nos interessa mais pensar o significado simbólico dos trabalhadores em cargos importantes do Governo peronista. O significado pode ser compreendido a partir de dois aspectos mais amplos: o reforço de imagens como um governo de e dos trabalhadores; e, consequentemente, o reforço de imagens de apoio, coesão e lealdade, a partir do fortalecimento dos laços entre Perón e os trabalhadores, uma vez que ele seria o primeiro governante a dar a oportunidade aos trabalhadores de atuar no Governo. Além de diferenciar também as imagens produzidas e reproduzidas no varguismo e no peronismo, isto é, o varguismo como um governo para os trabalhadores e o peronismo como um governo para, de e dos trabalhadores.

Outro aspecto distinto foi a projeção das imagens do discurso oficial sobre Perón. $\mathrm{Na}$ Argentina, até mesmo pelos acontecimentos que relacionaram Perón aos trabalhadores, como o de 17 de outubro de 1945, e por ter sido eleito presidente a partir de um partido dos trabalhadores, o Partido Laborista, não foi possível apagar a história dos trabalhadores ou parte dela, pois lhe auxiliou a chegar à presidência e constituía base de apoio significativo ao novo governo. Deste modo, pelo discurso oficial, Perón tentou se apropriar da luta dos trabalhadores, colocando-se como o grande condutor.

No tocante aos discursos políticos de Perón, o que se assemelha nos discursos políticos de Vargas, além da autodenominação como "primeiros" a considerar os trabalhadores, é a demarcação do tempo e da diferença entre a situação daquele momento em contraste com a anterior, como podemos notar a partir do trecho:

(6) Com exceção do primeiro ano, 1938, em que discursou Luis Augusto França, o presidente da União dos Sindicatos dos Empregados do Distrito Federal. 
Pasan por mi memoria tantos primeros de mayo desde 1910. Siendo estudiante he presenciado los primero de mayo más trágicos de toda la historia del trabajo argentino. Los veo ressurgir en 1916, 1917, 1918; Y los veo también mucho después, cuando las masas argentinas llegaban a esta plaza para reclamar justicia, desilusionadas por su destino ingrato; justicia que nunca obtenían, que nunca les alcanzaba. Cuántas veces he presenciado con dolor, a través de casi mis cincuenta y dos años de vida, el desfilar de esa lucha que el proletariado argentino libró, generación trás generación, por afirmar conquistas que no significaban más que la realización de una justicia fundamental y primaria, reclamada por quién trabaja y todo lo producía ante la negativa de quien todo lo disfrutaba y lo usufructuaba (PERÓN, SD, p. 37).

O "tempo novo" era composto por uma "nova" Argentina, um "novo" homem e, por essa razão, os trabalhadores não poderiam ter as mesmas representações do momento anterior. A marcação do novo tempo argentino, iniciado em 1943, em oposição ao anterior, revela não apenas outro posicionamento do governante diante da classe trabalhadora como também novas formas de se referir e se relacionar com ela, agora, como força política e social do governo.

Entre as imagens dos trabalhadores que aparecem nesses discursos políticos do "novo" tempo estavam a de unidos, leais, sinceros, dignos, conscientes e alegres. Com relação às imagens, notemos a retomada que propiciou o "novo" tempo:

Desfilan por nuestra imaginación y por nuestro recuerdo los días vividos a través de las etapas reivindicatorias de la Patria que comenzaron en junio de 1943. Primero, las reformas que fueron como la iniciación y la siembra de la simiente que había de cristalizar y florecer a lo largo del trabajo y sudor argentino. Después, el gobierno, nuestro gobierno, el gobierno del pueblo, el gobierno de los descamisados, el gobierno de los pobres, de los que tienen hambre y sed de justicia. Por eso, en esta plaza, la histórica Plaza de Mayo de todas nuestras epopeyas, han latido al unísono amalgamados en un solo haz todos los corazones humildes que por ser humildes son honrados, son leales y son sinceros. Después, la Constitución, la Constitución Justicialista, que ha hecho de la tierra argentina una Patria sin privilegios y sin escarnios; que ha hecho del pueblo argentino un pueblo unido, un pueblo que sirve al ideal de una nueva Argentina, como no la han servido jamás en nuestra historia. Esas tres etapas vividas por el pueblo argentino: la reforma, el gobierno y la Constitución argentina, nos han dado un estado de justicia y un estado de dignidad y nosotros los transformaremos en un estado de trabajo (PERÓN, 1949, SP).

Podemos, então, observar a relação direta que Perón estabelecia entre as suas ações, as ações do Governo, com a nova situação do trabalhador. Este trecho reúne as imagens de lealdade, sinceridade, amizade, dignidade e justiça social, demonstrando como tais imagens eram complementares e combinadas, compondo o "novo" trabalhador. Nos discursos políticos estudados, estas imagens, ainda que fossem apresentadas de forma separada, estavam sempre relacionadas à figura de Perón, do governo ou do movimento peronista.

Com relação à retórica de seus discursos políticos, para James (2013), Perón se diferenciava de caudilhos ou caciques políticos tradicionais, pois proclamava que o Es- 
tado só poderia ser uma força social, defensor dos direitos sociais, se os trabalhadores tivessem unidos e organizados em torno e dentro dele, isto é, o Estado era o espaço onde os trabalhadores, como força política, poderiam atuar político e socialmente para estabelecer as suas exigências e garantir seus direitos. Estas imagens reforçavam o papel do trabalhador para atingir o "lema" peronista: país socialmente justo, economicamente livre e politicamente soberano.

Vale dizer que, tal como no varguismo, houve uma apropriação da data emblemática dos trabalhadores para frisar o "novo" tempo:

Este 1ํ de mayo, el primero desde que me encuentro en el Gobierno, lo festejamos como fiesta incorporada a las grandes efemérides de nuestra Patria. Lo festejamos como el advenimiento de una nueva era para esta Patria tan amada, por la que trabajamos sin descanso día y noche, si es preciso (...). En este $1^{\circ}$ de mayo hemos alcanzado esa paz y tranquilidad provisorias. Hemos logrado conformar la conciencia social de nuestro pueblo, donde un gobierno de trabajadores marcha al frente de la columna obrera más grande que pueda haberse formado en esta tierra (PERÓN, 2002, p. 40).

Como podemos notar, o trecho revela o novo tempo da Argentina peronista combinada com imagens do discurso oficial de um governo de trabalhadores. Ademais, também devemos ressaltar a apropriação da própria história dos trabalhadores argentinos, sendo que o grande condutor desta "outra" história era Perón. Novamente, vale assinalarmos a outra face do discurso oficial, isto é, a censura e repressão aos trabalhadores que não estavam com o governo.

A legislação trabalhista e a política social também foram amplamente utilizadas. Entre as leis trabalhistas criadas, figuram: 13ํㅗalário; fixação do salário diário para os acidentados no trabalho; lei do salário mínimo; regime de trabalho para menores; cobrança de salários nos feriados; férias anuais remuneradas para todos os trabalhadores; criação do Instituto Nacional de Previdência Social e da Administração Nacional da Moradia para os trabalhadores; aprovação do regime legal das Associações Profissionais, que regulamentavam o funcionamento dos sindicatos; além da criação do Tribunal Superior do Trabalho. Estas políticas seriam reunidas nos direitos dos trabalhadores na Constituição de 1949. Além destas leis, devemos recordar o centro de políticas sociais associadas à Fundación Eva Perón, atuando nos campos da saúde, da educação, do turismo e da assistência social.

O papel, a imagem e o significado da cidadania também foram utilizados e são essenciais para a compreensão do período. Para James (2013), o atrativo político fundamental do peronismo residia na sua capacidade em redefinir a noção de cidadania, dentro de um contexto mais amplo, essencialmente social. Ainda de acordo com o autor, no discurso peronista, a cidadania não deveria mais ser definida apenas em função dos direitos individuais e as relações dentro da sociedade política, mas sim em função da esfera econômica e social da sociedade civil, assinalando a importância da justiça social, da garantia dos direitos sociais do povo argentino. Ademais, tal como no varguismo, cidadania implicava também em pertencer a uma totalidade, relacionada diretamente à identidade nacional argentina. 
Apesar desse aspecto em comum, Capelato (2009) apresenta a distinção entre as perspectivas da cidadania no varguismo e no peronismo:

A política varguista iniciada uma década antes da peronista e, portanto, numa conjuntura diversa, apresenta distinções já identificáveis nas denominações "justicialismo" e "trabalhismo". Enquanto na Argentina, a "justiça social" foi o carro-chefe do peronismo, no Brasil, ela ocupou um papel secundário já que o objetivo principal do novo regime era a reforma do Estado com vistas ao desenvolvimento econômico e à disciplinarização da força de trabalho. Isso não significa que o Governo não tenha introduzido modificações importantes no mundo do trabalho, mas elas são modestas quando comparadas com as ocorridas na Argentina (CAPELATO, 2009, p. 214).

Outro fator que contribuiu para as modificações importantes no mundo do trabalho foi a situação econômica distinta nos dois países, como mencionamos no início desta parte (CAPELATO, 2009). No caso argentino, o contexto econômico favorável tornou possível a percepção real da melhora das condições de vida dos trabalhadores.

A tônica argentina também auxilia na compreensão da formulação da doutrina e cultura política justicialista. Como procuramos demonstrar até o momento, ainda que em bases distintas do trabalhismo varguista, o justicialismo peronista também pode ser compreendido como um conjunto de ideias, valores, rituais e vocabulários vinculados à justiça social. A partir do discurso oficial, podemos observar que o justicialismo também lança raízes na experiência do movimento operário e sindical dos anos anteriores a 1943, mas, diferentemente de Vargas, Perón não negaria a experiência, mas se apropriaria e se colocaria como o grande condutor dos trabalhadores. Os usos, as apropriações e as ressignificações do justicialismo também podem ser notados na Argentina atual.

As novas imagens sobre os trabalhadores combinadas com a legislação trabalhista e políticas sociais dariam o tom da reinvenção. As imagens e a legislação seriam intensificadas no segundo governo de Perón, em razão da debilidade da situação econômica e, consequentemente, política. No caso da situação econômica, com o término da Segunda Guerra Mundial, por distintos fatores, foi iniciada uma crise do setor externo argentino, que teve consequências na atividade industrial nacional, pela dificuldade de importar máquinas e equipamentos, impulsionando a inflação. Além disso, os subsídios públicos foram cortados e os salários reais começaram a declinar, o que ocasionou uma sucessão de greves. Diante desse cenário, o Governo peronista mudaria algumas de suas políticas, sobretudo com relação à atração de capitais estrangeiros, promovendo inclusive uma campanha que diminuía as restrições a importações de máquinas e equipamentos, tal como o envio dos dividendos para fora do país (BAILY, 1986).

O cenário de "mundo feliz" do primeiro governo já não existia mais e, assim, o segundo governo enfrentaria maiores dificuldades com os trabalhadores. As greves dos trabalhadores somadas ao acirramento da oposição sindical e à morte de Eva Duarte Perón contribuiriam para o cenário complexo instaurado. Decorrente do contexto exposto, os discursos políticos a partir de 1952 teriam um tom mais agressivo do que os 
apresentados até o momento. Perón convocava, explicitamente, os trabalhadores para uma batalha contra os inimigos internos e externos da Argentina:

Compañeros: Estamos en un momento en que todos debemos de preocuparnos seriamente, porque la canalla no descansa, porque están apoyados desde el exterior. Decía que es menester velar en cada puesto con el fusil al brazo. Es menester que cada ciudadano se convierta en un observador minucioso y permanente porque la lucha es subrepticia. No vamos a tener un enemigo enfrente: colocan la bomba y se van. Aumentan los precios y se hacen los angelitos. Organizan la falta de carne y dicen que ellos no tienen la culpa (PERÓN, 1952, SP).

A partir do segundo Governo, também ficaria mais evidente a oposição entre um "nós" pleno, substancial, que coincide com o coletivo "argentino", "pátria", e um "eles" pleno, racional, que coincide com o coletivo "antiargentino", "antipátria". O adversário não tinha um projeto político, mas era aquele que colocava obstáculos ao projeto político de Perón, coincidente com a verdade e a realidade argentina.

\section{CONSIDERAÇÕES FINAIS}

Procuramos estudar os imaginários sociais sobre os trabalhadores no varguismo e no peronismo, propondo uma ideia de reinvenção sobre os trabalhadores nestes momentos. Ao longo do trabalho, também tentamos demonstrar as proximidades e afastamentos entre estas reinvenções.

Em alguma medida, refletir sobre tais reinvenções é também refletir sobre as distintas formas de produção e reprodução dos discursos oficiais sobre os trabalhadores. Com relação aos discursos oficiais, vale assinalar, como procuramos demonstrar na introdução deste trabalho, que tais discursos, compreendidos como uma forma de expressar os imaginários sociais, não necessariamente, correspondem à "verdadeira" atuação ou história dos trabalhadores nestes momentos. Tais discursos oficiais selecionaram determinados elementos e forjaram uma versão específica destes momentos: as suas, ou seja, a do varguismo e a do peronismo e, em nosso caso, a de Vargas e de Perón. Portanto, este trabalho compõe uma das versões forjadas sobre o varguismo e o peronismo e a relação com os trabalhadores, possível de análise e reflexão, em um primeiro momento, e de comparação ou contraposição com outras versões, em estudos posteriores.

Com relação aos imaginários sociais apresentados, ainda que buscassem atingir os "corações" e "mentes" dos trabalhadores e produzir imagens de apoio, coesão e legitimidade destes governos, vale assinalarmos que não consideramos recepções homogêneas, senão múltiplas, complexas e não lineares, justamente pela importância do sentido destas produções.

A multiplicidade destes fenômenos pode ser observada a partir daqueles estudos que utilizaram as cartas enviadas a Vargas e a Perón, como os de Ferreira (1997) e Marcus Dezemone (2006), onde é possível notar que os resultados destas produções são imprevisíveis e o fazer crer e o querer crer a partir destes discursos políticos selecionados nem sempre estão juntos com o crer. 


\section{BIBLIOGRAFIA}

BACZKO, Bronislaw. A imaginação social In: LEACH, Edmund. Anthropos-Homem. Lisboa, Imprensa Nacional/Casa da Moeda, 1985.

BAILY, Samuel. Movimiento obrero, nacionalismo y política en la Argentina. Buenos Aires: Paidós, 1986.

CAPELATO, Maria Helena Rolim. Multidões em cena: propaganda política no varguismo e no peronismo. São Paulo: Editora UNESP, 2009.

CHARAUDEAU, Patrick. Discurso Político. São Paulo: Contexto, 2013.

CONTRERAS, Gustavo Nicolás; MARCILESE, José (org.). Dossier Los trabajadores durante los años del primer gobierno peronista. Nuevas miradas sobre sus organizaciones, sus prácticas y sus ideas (19461955). Disponível em:<http://historiapolitica.com/dossiers/trabajadores-peronismo/>.

DEZEMONE, Marcus. Do cativeiro à reforma agrária: colonato, direitos e conflitos. 2008. 299p. Tese (Doutorado em História). Instituto de Ciências Humans e Filosofia, Universidade Federal Fluminense, Niterói-RJ, 2008.

FERREIRA, Jorge. Trabalhadores do Brasil. O imaginário da cultura popular (1930-1945). Rio de Janeiro: FGV, 1997.

FERREIRA, Jorge. O Populismo e sua História: Debate e Crítica. Rio de Janeiro: Ed. Civilização Brasileira, 2001.

GERMANI, Gino. Políticay sociedad en unaépoca de transición. De la sociedad tradicional a la sociedad de masas. Buenos Aires: Paidós, 1962.

GOMES, Angela de Castro. A invenção do Trabalhismo. Rio de Janeiro: Relume Dumará, 2002.

JAMES, Daniel. Resistencia e integración: el peronismo y la clase trabajadora argentina. Buenos Aires: Siglo Veintiuno Editores, 2013.

LAGO, Mayra Coan. Trabalhadores do Brasil, Mis Queridos Descamisados: a (re)invenção dos trabalhadores no varguismo e no peronismo. Dissertação de Mestrado (Mestrado em Integração da América Latina). Programa de Pós-graduação Interunidades em Integração da América Latina da Universidade de São Paulo-SP, 2015.

MURMIS, Miguel; PORTANTIERO, Juan Carlos. Estudios sobre los orígenes del peronismo. Buenos Aires: Siglo Veintiuno, 2012.

PERÓN, Juan Domingo. "Cuadernillos de formación político-sindical, número 02". Obras completas del General Juan Domingo Perón. Discursos de Juan D. Perón, 1946-1947. Buenos Aires: Unión del Personal Civil de la Nación, s/d.

TORRE, Juan Carlos. Ensayos sobre movimiento obrero y peronismo. Buenos Aires: Siglo veintiuno, 2012.

VARGAS, Getúlio. Getúlio Vargas. Maria Celina D`Araújo (org). Brasília: Câmara dos Deputados, Edições Câmara, 2011.

WEBER, Max. A política como vocação. In: WEBER, Max. Ciência e política - duas vocações. São Paulo: Cultrix, 2004.

WEFFORT, Francisco. O populismo na política brasileira. Rio de Janeiro: Paz e Terra, 2003. 